\title{
Brainwave Controlled Electrical Wheelchair
}

\author{
Sim Kok Swee, Lim Zheng You,Kho Teck Kiang
}

MMU University, Faculty of Engineering \& Technology, 75450 Melaka, Malaysia

\begin{abstract}
Electrical wheelchair provides mobility to the people who lost their moving capability. To allow most of the people to be able to control the electrical wheelchair, the best solution is by directly using the brain instead of using joystick or buttons. The first objective of this project is to provide the basic mobility by constructing an electrical wheelchair. The second objective is to process the electroencephalogram (EEG) signals for controlling purpose. The EEG device which used in this project to capture the signals is the Emotiv EPOC headset. A computer is used to receive and process the EEG signals, then send the control signal to the microcontroller of the electrical wheelchair. All the hardware are connected wirelessly via Bluetooth.
\end{abstract}

\section{Introduction}

Nowadays in Malaysia, the number of disabled individuals are increasing every year. According to the statistics of Department of Social Welfare Malaysia, it states that the numbers of physical disabled individuals are increasing from the year of 2008 to 2011[1]. There are 445,006 people with disabilities registered In Malaysia as of 2012[2]. This also shows that the number of persons who lost their mobility are significant. To regain the mobility, the most common solution is by using a wheelchair. However today, most of the wheelchair requires user's hand to maneuver. Even for the electrical wheelchair, it still requires user's finger to control the joystick or button [3]. Therefore, some patients who completely lost their hands or those who suffer from Poliomyelitis disease will face the difficulties to control the wheelchair. In this way, they are unable to navigate themselves around. In order to overcome this problem, an alternative way that will enable most of the people to navigate the wheelchair is directly controlled by the brain. Therefore, this will bring an extremely high impact, especially for disabled individuals who cannot otherwise physically communicate [4].

In order to allow the brain to directly controlling the wheelchair, it requires the information of the brain activity. There are several ways to retrieve the signals of brain activity. They are Positron Emission Tomography [5], Single Photon Emission Tomography, Electroencephalography and Functional Magnetic Resonance Imaging. Among these methods, EEG is the best method to retrieve the signal of brain activity. This is because the EEG device is portable and non invasive [6].
Electroencephalogram (EEG) is a method which records electrical waveform from the brain by using electrodes appropriately placed on the head. It measures voltage fluctuations resulting from ionic current within the neurons of the brain [7]. This method records electrical motivations from the nerves of the brain. [8]. According to the human thoughts, different electrical waves are produced. Even for a muscle contraction, it will also generate a unique electrical signal [9]. These signals are further processed to determine the mental commands from the user's brain.

After signal processing, the mental commands such as forward, backward, left and right[10] can be used as controlling signals to control the movement of electrical wheelchair. This is a method which translate brain signals into control commands, also known as Brain-computer interfaces (BCIs) [11].

\section{Problem statement}

To provide basic mobility to the people who completely lost their hands and unable to move by themselves, brainwave controlled electrical wheelchair is the best solution. However, nowadays, a good EEG device is still relatively costly. Therefore, more researches have to be done for producing a suitable but affordable EEG device.

\section{Design}

The basic hardware design is the design of the electrical wheelchair mechanical structure. This project 
also involves designing electronic circuits for the electronic system of the electrical wheelchair. Software development is required for retrieving the signals from EEG device and further processing the signals to determine the mental commands. The software development also involves writing the program of the Arduino microcontroller on the electrical wheelchair so that electrical wheelchair performs the correct movement.

\subsection{Hardware Design}

Most of the wheelchairs available in the market have dimension around 36 inches ( 3 feet) long and 24 inches ( 2 feet) wide. In order to meet the standard size of the wheelchairs, the size of the base of prototype is 36 inches (3 feet) long and 24 inches ( 2 feet) wide. To achieve stability but considering the weight of the wheelchair, the material used to construct the wheelchair base and frame is steel hollow tube. The armrest, backrest and seat are covered by PVC leather for comfort purpose.

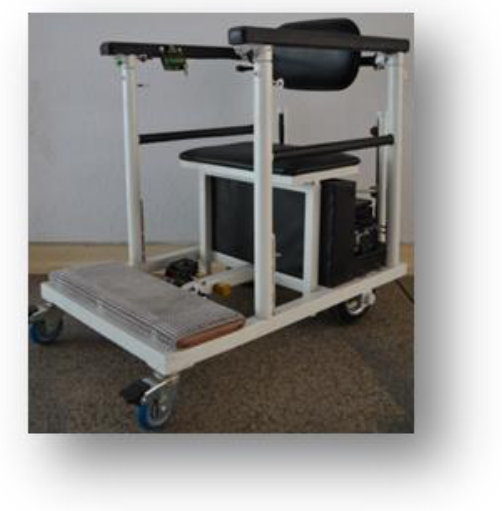

Figure 1. The Structure of Wheelchair.

The electrical wheelchair is designed with back wheel differential driven. Since the motors need to carry a person and also the whole structure, high torque motor are required. Therefore, scooter motors are chosen.

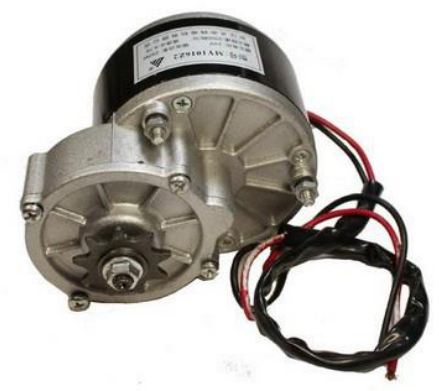

Figure 2. Scooter Motor with Gear

Arduino Uno microcontroller board is chosen as the main controller of the electrical wheelchair. This microcontroller is chosen as it has enough $\mathrm{I} / \mathrm{O}$ pins for controlling the entire electrical wheelchair system and is relatively small size.

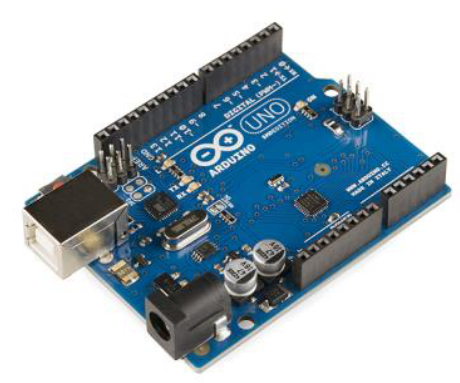

Figure 3. Arduino Microcontroller

Since scooter motor is used, a high current motor driver is required for driving the scooter motor. This is because the scooter motor will draw high current up to 10 ampere. A relays circuit board is also used for controlling the other motors such as power window motor on the electrical wheelchair.

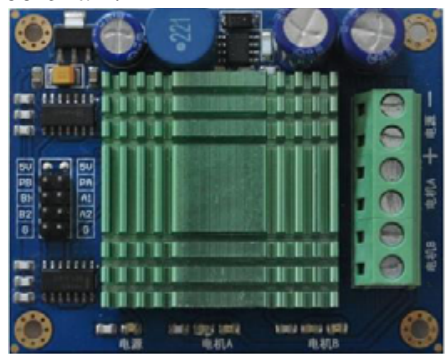

Figure 4. High Current Motor Driver

Bluetooth module HC06 is used for wireless communication. This module connects to the Arduino microcontroller. This allows PC and smartphone to directly connect to it and receive the command signals.

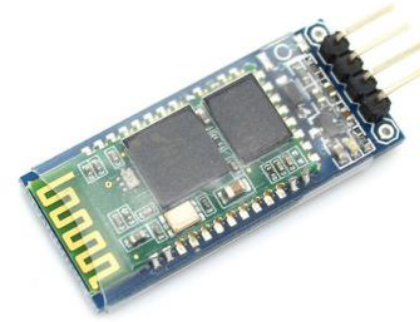

Figure 5. HC-06 Bluetooth module.

Emotiv EPOC is the EEG device used to record and transmit the EEG signals. Emotiv EPOC is the official headset from Emotiv. It contains 14 channels, which means 14 sensor electrodes.

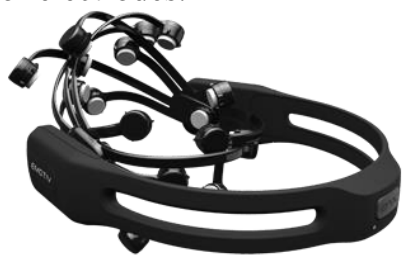

Figure 6. Emotiv EPOC headset. 


\subsection{Software Design}

For schematic diagram design and PCB design, the Easy Applicable Graphical Layout Editor (EAGLE) is used. The openness of EAGLE design resources, such as its extensive and fully-open component libraries, ease the design process for all. [12]

Arduino Integrated Development Environment (IDE) [13] is used for compiling and uploads the source code to the Arduino Uno microcontroller. This software is opensource and is easy to upload code as it only requires USB cable, no extra circuit needed.

Microsoft Visual C\# [14] is the IDE supports Visual C\# with a full-featured code editor, compiler. It is a used to write the program for receiving the data sent from EEG device, processing the data and sending the command signal to the microcontroller via Bluetooth.

Android Studio is used to write an Android application which can be installed in smartphone to send the command signal to the microcontroller via Bluetooth without using the PC.

\subsection{Methodology}

The first step of the project is to select a best EEG device for reading the EEG signals. There are several EEG devices that can be found in the market. The comparison between the devices is done in table 1. From the comparison, it is found that the most suitable EEG device is the Emotiv EPOC headset as it contains the most channels among all these devices.

\begin{tabular}{|c|c|c|c|c|}
\hline Device & Open EEG & Mindflex & $\begin{array}{l}\text { Neurosky } \\
\text { Mindset }\end{array}$ & Emotiv EPOC \\
\hline Description & $\begin{array}{l}\text { Building } \\
\text { the EEG } \\
\text { device and } \\
\text { software } \\
\text { from } \\
\text { scratch }\end{array}$ & $\begin{array}{l}\text { Levitating } \\
\text { ball game } \\
\text { from } \\
\text { Mattel }\end{array}$ & $\begin{array}{l}\text { Official } \\
\text { headset } \\
\text { from } \\
\text { Neurosky }\end{array}$ & $\begin{array}{l}\text { Official headset from } \\
\text { Emotiv }\end{array}$ \\
\hline $\begin{array}{l}\text { Attention/ } \\
\text { Meditation } \\
\text { Value }\end{array}$ & No & Yes & Yes & Yes \\
\hline $\begin{array}{l}\text { Developer } \\
\text { Tool }\end{array}$ & $\begin{array}{l}\text { Yes and } \\
\text { free }\end{array}$ & No & $\begin{array}{l}\text { Yes, } \\
\text { included } \\
\text { with the } \\
\text { purchase }\end{array}$ & $\begin{array}{l}\text { Yes, included with the } \\
\text { purchase }\end{array}$ \\
\hline EEG channel & $\begin{array}{l}\text { Depends } \\
\text { on } \\
\text { developer }\end{array}$ & 1 channel & 1 channel & 14 channel \\
\hline Costs & $\begin{array}{l}\text { More than } \\
\$ 200\end{array}$ & $\$ 50$ & $\$ 199$ & $\$ 399$ \\
\hline
\end{tabular}

Table 1 Comparison between EEG devices which found in commercialized market

The following step is the development of the electrical wheelchair. This development process involves the construction of mechanical structure of the wheelchair and also electronics circuit design. Besides, this process also involves software programming design for the microcontroller board so that microcontroller board will send appropriate control signals to the motor driver.

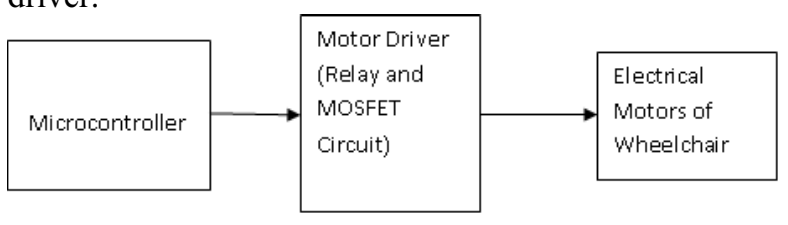

Figure 7. Block diagram of Electrical Wheelchair System

The entire electronic system includes few main devices. They are EEG device, computer and microcontroller of the electrical wheelchair. The interconnection of these devices is shown in the figure 8 .

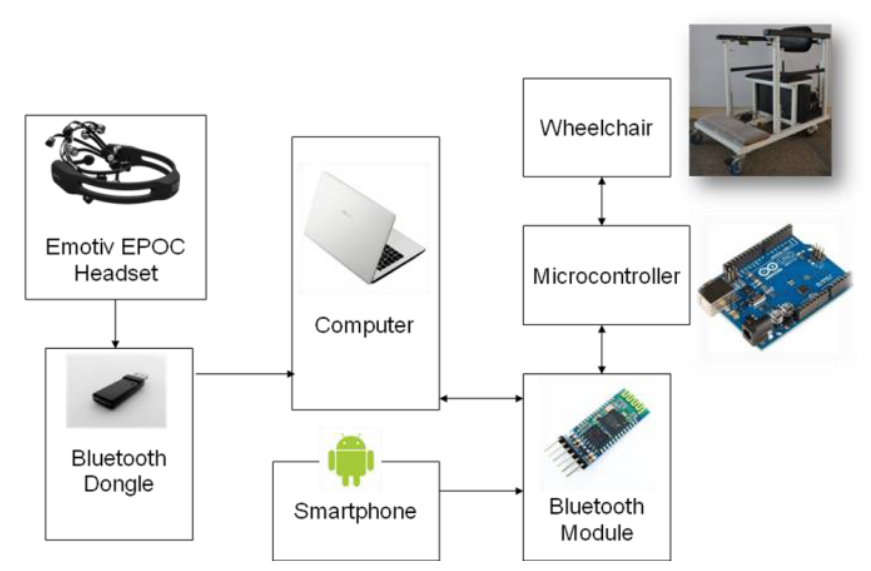

Figure 8. Block diagram of the complete brain controlled wheelchair system

The Emotiv EPOC headset is placed on the user's head for recording the EEG signals of the brain. The Bluetooth dongle is plugged in to the PC. It is used to connect with the Emotiv EPOC headset. In this way, the $\mathrm{PC}$ is able to receive the data sent from the Emotiv EPOC headset. The received data is further processed by using the application that wrote by using Microsoft Visual C\#. The data is further processed to determine the mental command that is thinking by the user. According to the mental commands, output command signal is generated. Then, the command signal is sent to the microcontroller of the electrical wheelchair via Bluetooth. In this way, the electrical wheelchair is able to be directly controlled by the user's brain. Besides, an Android software can be also used to control the movement of the electrical wheelchair without require PC for sending command signal. However, the Android application is still not able to receive and process the EEG signals.

The program flowchart (shown in figure 9) shows that the electrical wheelchair is able to operate in two modes. One is by using the brainwaves to control and another mode is by using an Android application to control. The smartphone Android application is an extra feature that allows the user to control the electrical wheelchair like a common electrical wheelchair instead of the electrical wheelchair is only workable under the brainwaves control. Therefore, this program flow involves few software developments. First, a Windows 
based application is developed by using Microsoft Visual $\mathrm{C \#}$ for receiving and processing the incoming signals from EEG device. After processed the signals, the application generates control signal and send to the microcontroller of the electrical wheelchair via Bluetooth. Therefore, the program of the Arduino microcontroller have to be written properly so that it will send appropriate signals for controlling the wheelchair movement. This program is written and compiled by using Arduino IDE.

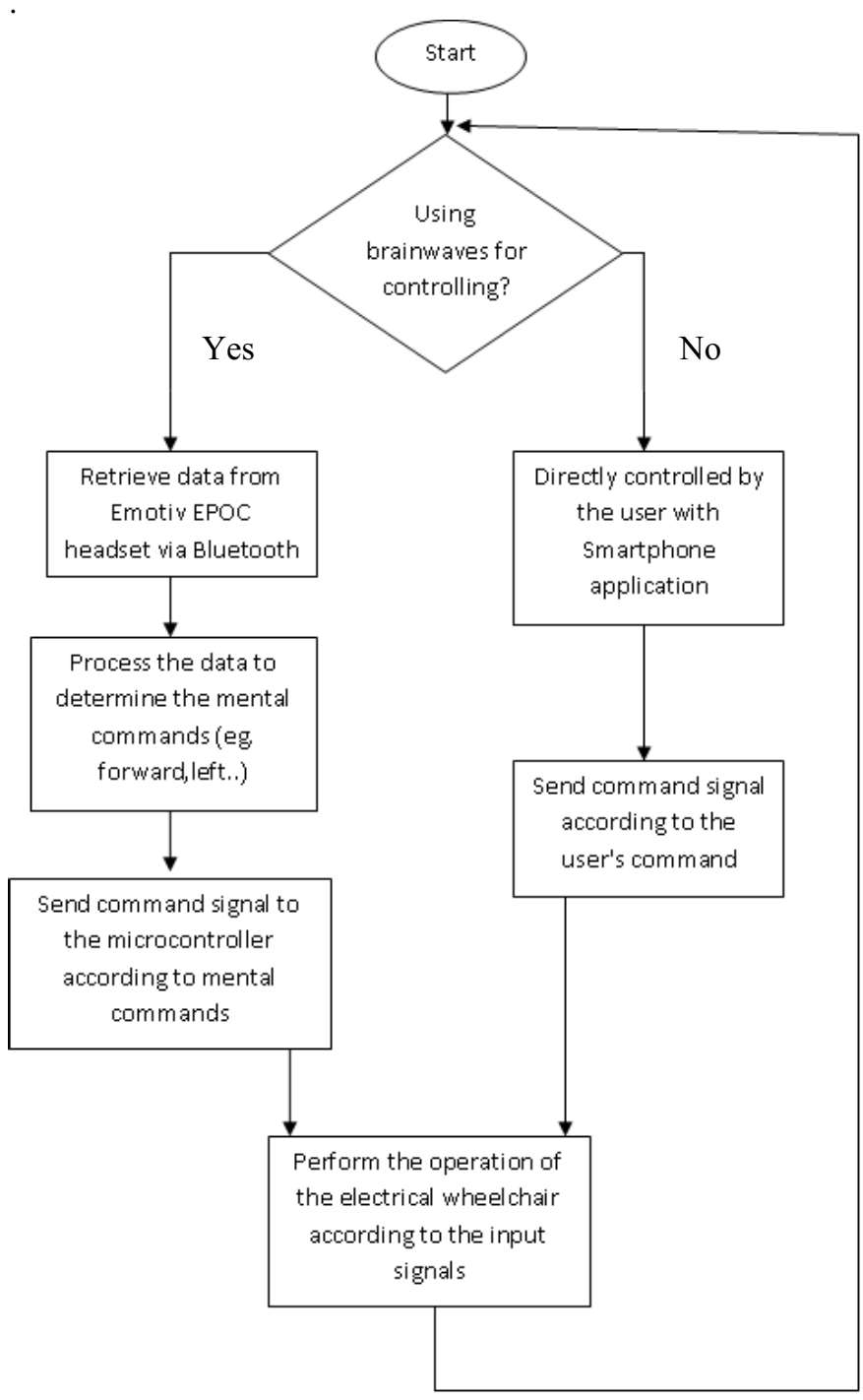

Figure 9. Main program flow of the brainwave controlled wheelchair system.

\section{Results}

The developed electrical wheelchair is able to be controlled directly by the brain. In addition, this electrical wheelchair is also able to work as normal electrical wheelchair by using the developed Android application. This project provides a new and effective solution for the people who lost their hands and mobility.
1. Public Service Department Malaysia, "What Is The Definition Of Senior Citizens In Malaysia?"[Online].Available:

http://www.jpapencen.gov.my/english/senior_cit izen.html. [Accessed: 01-Dec-2013].

2. Unicef, "Situation in Malaysia." [Online]. Available:

http://www.unicef.org/malaysia/sowc sowc 13situation_in_malaysia.html. [Accessed: 29-Sep2015].

3. L. Bi, X. A. Fan, Y. Liu "EEG-Based Braincontrolled Mobile Robots: A survey", HumanMachine Systems, 43, 161-176, (2013).

4. A. Nijholt, D. Tan, G. Pfurtscheller, C. Brunner, J.del R. Mill'an, B. Allison, B. Graimann, F. Popescu, B. Blankertz, and K.-R. M"uller, "Brain-computer interfacing for intelligent systems.", IEEE Intelligence System, 23, 72-79. (2008).

5. WebMD. "Positron Emission Tomography (PET)." [Online]. Available: http://www.webmd.com/cancer/lymphoma/posit ron- emission- tomography. [Accessed: 9Sep-2014].

6. T. F. Collura. "EEG Frequency Bands." The Measurement, Interpretation, and Use of EEG Frequency Bands. (1997).

7. E. Niedermeyer \& B. F L. Silva. "Electroencephalography: Basic Principles, Clinical Applications and Related Fields." (2005).

8. K. H. Solanki, H. Pujara. "Brainwave Controlled Robot.", International Research Journal of Engineering and Technology (IRJET), 2, 609 612. (2015).

9. K. Yendrapalli , S. S. N. P. K. Tammana The "Brain Signal Detection for Controlling the Robot.", International Journal of Scientific Engineering and Technology, 3, 1280-1283. (2014).

10. B. Rebsamen, C. Guan, H. Zhang, C. Wang, C. Teo, M. H. Ang, Jr., and E. Burdet, "A brain controlled wheelchair to navigate in familiar environments.", IEEE Trans. Neural Syst. Rehabil, 18, 590-598. (2010).

11. K.. R. M"uller and B. Blankertz, "Toward noninvasive brain-computer interfaces," IEEE Signal Processing Magazine, 23, 125-128. (2006).

12. CSEagle, "What is EAGLE." [Online]. Available: http://www.cadsoftusa.com/eaglepcb-design-software/about-eagle/ [Accessed: 29Sep-2015].

13. Arduino LLC, "Arduino Software IDE." [Online]. Available: http://www.arduino.cc. [Accessed: 27-Aug-2015].

14. "Microsoft Visual C\#," Microsoft, 1989. [Online]. Available: http://msdn.microsoft.com [Accessed: 27-Aug-2015].

\section{References}

